\title{
$24 \sqrt{\text { Effectiveness and hazards of case finding for a high cholesterol }}$ concentration //
}

\author{
Scott|Kinlay, Richard F Heller
}

\begin{abstract}
Objective-To see whether adults with high blood cholesterol concentrations $(>6.5 \mathrm{mmol} / \mathrm{l})$ detected by case finding return to their doctor, receive appropriate advice, and report changes in their diet and whether adults found not to have high cholesterol concentrations on case finding are discouraged from changing their diet.

Design-Follow up study.

Setting-Seven general practices in the lower Hunter region of Australia.

Participants-600 Men and women aged 25-65 who had their blood cholesterol concentrations measured three to four months earlier while attending their general practitioner. Analysis conducted on $552(92 \%)$ who returned follow up postal questionnaires.
\end{abstract}

Measurements and main results-Of the 125 subjects found to have blood cholesterol concentrations greater than $6.5 \mathrm{mmol} / \mathrm{l}, 102(82 \%)$ returned to their doctor and 83 of these recalled receiving dietary advice. $93(75 \%)$ Subjects with high concentrations reported changing their diet compared with $72(46 \%)$ subjects with concentrations of $>5 \cdot 5-6 \cdot 5 \mathrm{mmol} / 1$ and $44(17 \%)$ subjects with lower concentrations. Overal not changing their diet, the most common reason (nearly half the sample; $n=266$ ) being that their cholesterol concentration was "all right." Adults without high cholesterol concentrations who returned to their doctor were also significantly more likely to recall their doctor saying that they did not need to lower their concentrations $(\leqslant 5.5 \mathrm{mmol} / \mathrm{l}=$ $61 \% ;>5 \cdot 5-6 \cdot 5 \mathrm{mmol} / \mathrm{l}=12 \% ;>6.5 \mathrm{mmol} / \mathrm{l}=5 \%)$ and significantly less likely to recall receiving dietary advice $(\leqslant 5.5 \mathrm{mmol} / \mathrm{l}=13 \% ;>5 \cdot 5-6.5 \mathrm{mmol} / \mathrm{l}=60 \%$; $>6.5 \mathrm{mmol} / \mathrm{l}=82 \%$ )

Conclusions-High risk strategies which require everyone to be tested for high cholesterol concentrations may interfere with population strategies designed to reduce everyone's dietary intake of fat.

Centre for Clinical Epidemiology and Biostatistics, Faculty of Medicine, David Maddison Building, UUniversity of Newcastle, Newcastle] NSW] 2308, Australia] Scott Kinlay, MB, [National Health and Medical Research Council training fellow Richard F Heller, FRCP, professor of community medicine

Correspondence and requests for reprints to: $\mathrm{Dr}$ Kinlay.

BrMed 7 1990;300:1545-7

\section{Introduction}

Case finding for a high blood cholesterol concentration means that a person has a blood cholesterol test arranged while he or she is attending the doctor for an unrelated problem. In Australia, the United Kingdom, and North America case finding is the preferred method of identifying patients with high cholesterol concentrations and is a principal component of heart disease prevention programmes. ${ }^{1.3}$ A high blood cholesterol concentration is defined as over $6.5 \mathrm{mmol} / \mathrm{l}$ in Australia and Europe ${ }^{2}$ and over $6.2 \mathrm{mmol} / \mathrm{l}$ in North America.

Identifying patients with high cholesterol concentrations, however, will not alone lead to a reduction in their risk of heart disease. High risk subjects need to $333(61 \%)$ of all respondents who answered reported

change their diet to reduce the concentrations and avoid other important risk factors. They may also benefit from agents that reduce blood lipid concentrations if their blood cholesterol concentration remains high. Because of these factors and the difficulty in interpreting a single test result (owing to the large intraindividual variation in lipid values ${ }^{4}$ ) most authorities would recommend that patients with high cholesterol concentrations should be managed by their doctor to maximise their risk reduction. Thus the success of case finding as a strategy for preventing heart disease depends on whether those identified return to their doctor, receive appropriate advice, and make the required changes in their lifestyle.

The burden of illness from heart disease, however, is unlikely to be reduced sufficiently by a high risk strategy alone. The other component to most national heart disease prevention programmes is the mass strategy of reducing everyone's risk of heart disease. This does not require the identification of risk factors but shifts the whole population's exposure to factors which increase everyone's risk (for example, a national diet high in fat) down to favourable levels. Many workers have suggested that this strategy has the greatest potential to reduce the incidence of disease because it operates on the whole population rather than a few people at high risk. ${ }^{56}$ It is important that the potential for population strategies should not be impeded by other strategies employed to prevent heart disease. For example, case finding may interfere by reassuring the majority of people without high cholesterol concentrations that they are "not at high risk" and therefore do not need to lower their risk.

This study aimed at determining whether adults who had been informed they had high blood cholesterol concentrations received appropriate advice and reported changes in their diet, and whether those without high cholesterol concentrations were less inclined to change their diet. We studied all adults aged 25-65 roughly three months after they had participated in a general practice study in which they had received their blood cholesterol concentration together with an interpretation based on current Australian guidelines.

\section{Methods}

The study population (described elsewhere ${ }^{7}$ ) consisted of 616 adults aged 25-65 who had attended one of seven general practices in the lower Hunter region of New South Wales from March to November 1987 Participants completed a questionnaire and had their height and weight measured and a blood sample taken after they had been seated for 10 minutes. Serum cholesterol concentration was measured by the Royal Newcastle Hospital biochemistry service using a standard enzyme kit.

All subjects received the result of the blood cholesterol measurement by letter within three to four weeks 
of their visit. The letter also informed the subjects that the National Heart Foundation of Australia recommended that all adults should have a cholesterol concentration below $5.5 \mathrm{mmol} / \mathrm{l}$ and that if theirs was above this they should try to reduce it. In addition, subjects with a concentration greater than $6.5 \mathrm{mmol} / \mathrm{l}$ were advised to return to their doctor for review and if necessary treatment. This advice was based on current Australian and European recommendations on the management of blood cholesterol concentrations. ${ }^{12}$ The letter did not provide any dietary advice. The participants' general practitioners were sent a copy of the results of their records.

Three to four months after participating in the study all subjects were posted a questionnaire asking $(a)$ whether they thought that their cholesterol concentration was high, $(b)$ whether they had seen their doctor since they received the result of their cholesterol estimation, $(c)$ what their doctor had said or done, and (d) whether they had changed their diet to reduce their cholesterol concentration. Participants who had not returned the questionnaire were reminded by telephone or letter at two weeks and sent another questionnaire four weeks after the date of the first one.

The questionnaires were coded and entered into the University of Newcastle computing system. Twelve women who were pregnant at the time of the initial survey and an additional four people in whom blood could not be obtained were excluded, leaving 600 subjects who formed the denominator of the study. Analysis using the biomedical programs data package (BMDP) consisted of descriptive statistics and in

TABLE I-Characteristics at initial examination of 552 men and women who returned follow up questionnaires

\begin{tabular}{lcc}
\hline & Men $(\mathrm{n}=181)$ & Women $(\mathrm{n}=371)$ \\
\hline $\begin{array}{l}\text { Mean }(\mathrm{SD}) \text { age }(\text { years }) \\
\begin{array}{l}\text { Mean }(\mathrm{SD}) \text { total cholesterol } \\
(\mathrm{mmol} / \mathrm{l})\end{array}\end{array}$ & $43 \cdot 0(12 \cdot 0)$ & $43 \cdot 0(12 \cdot 0)$ \\
$\begin{array}{l}\text { Mean }(\mathrm{SD}) \text { body mass index } \\
\left(\mathrm{kg} / \mathrm{m}^{2}\right)\end{array}$ & $5 \cdot 72(1 \cdot 15)$ & $5 \cdot 74(1 \cdot 19)$ \\
$\begin{array}{l}\mathrm{No}(\%) \text { of current smokers } \\
\text { No }(\%) \text { with history of } \\
\text { hypertension }\end{array}$ & $27 \cdot 0(4 \cdot 1)$ & $25 \cdot 9(5 \cdot 6)$ \\
\hline
\end{tabular}

TABLE II - Three month follow up of respondents' perceptions and actions in relation to initial cholesterol concentrations (whole sample; $n=552$ ). Values are numbers (percentages) of subjects

\begin{tabular}{lcccc}
\hline & \multicolumn{3}{c}{ Initial cholesterol concentration $(\mathrm{mmol} / \mathrm{l})$} & \\
\cline { 2 - 3 } & $\leqslant 5 \cdot 5(\mathrm{n}=264)$ & $>5 \cdot 5-6 \cdot 5(\mathrm{n}=163)$ & $>6 \cdot 5(\mathrm{n}=125)$ & Total \\
\hline $\begin{array}{l}\text { Thought concentration high or } \\
\quad \text { very high }\end{array}$ & $9 / 261(3)$ & $58 / 162(36)$ & $99 / 122(81)^{\star \star \star}$ & $166 / 545(30)$ \\
$\begin{array}{l}\text { Returned to doctor because of } \\
\quad \text { concentration }\end{array}$ & $48 / 262(18)$ & $58 / 162(36)$ & $102 / 124(82)^{\star \star \star}$ & $208 / 548(38)$ \\
$\begin{array}{l}\text { Changed diet to reduce } \\
\text { concentration }\end{array}$ & $44 / 260(17)$ & $72 / 158(46)$ & $93 / 124(75)^{\star \star \star}$ & $209 / 542(39)$ \\
\hline
\end{tabular}

Column totals differ because of incomplete answers in a few cases.

$\star \star \star p<0 \cdot 0001$ ( $\chi^{2}$ test $)$.

TABLE III-Doctors' comments and actions recalled by 208 men and women who revisited their doctor. Values are numbers (percentages) of subjects

\begin{tabular}{lccc}
\hline & \multicolumn{3}{c}{ Initial cholesterol concentration $(\mathrm{mmol} / \mathrm{l})$} \\
\cline { 2 - 4 } & $\leqslant 5 \cdot 5(\mathrm{n}=48)$ & $>5 \cdot 5 \cdot 6 \cdot 5(\mathrm{n}=58)$ & $>6 \cdot 5(\mathrm{n}=102)$ \\
\hline Recall of information given by doctor: & & & \\
$\quad$ Concentration high & $0 / 47$ & $19 / 55(35)$ & $78 / 99(79)^{\star \star \star}$ \\
No need to lower concentration & $27 / 44(61)$ & $6 / 49(12)$ & $5 / 96(5)^{\star \star \star}$ \\
$\quad$ Should/must lower concentration & $5 / 44(11)$ & $37 / 49(76)$ & $87 / 96(91)^{\star \star \star}$ \\
Further test arranged & $4 / 48(8)$ & $13 / 57(23)$ & $46 / 100(46)^{\star \star \star}$ \\
Advice given by doctor: & $6 / 45(13)$ & $33 / 55(60)$ & $83 / 101(82)^{\star \star \star}$ \\
Dietary & $5 / 45(11)$ & $13 / 55(24)$ & $40 / 101(40)^{\star \star}$ \\
Exercise & $6 / 45(13)$ & $5 / 55(9)$ & $14 / 101(14)$ \\
Stop smoking & $6 / 45(13)$ & $13 / 55(24)$ & $41 / 101(41)^{\star \star}$ \\
Reduce weight & $0 / 48$ & $1 / 56(2)$ & $13 / 99(13)^{\star \star}$ \\
Began lipid lowering drugs & & & \\
\hline
\end{tabular}

Column totals differ because of incomplete answers in a few cases.

${ }^{\star \star} p<0.01 ;{ }^{\star \star \star} p<0.001$ ( $\chi^{2}$ tests). comparing responses according to cholesterol concentrations of greater than $6.5 \mathrm{mmol} / \mathrm{l}$ (high), $>5.5$ $6.5 \mathrm{mmol} / \mathrm{l}$ (moderately high), and $5.5 \mathrm{mmol} / \mathrm{l}$ or less. The descriptive data were compared by using Yates's corrected $\chi^{2}$ test for categorical data and $t$ tests for continuous data. $\chi^{2}$ Tests with two degrees of freedom were used to test whether responses across the three groups of cholesterol concentration were significantly different, and $95 \%$ confidence intervals were calculated for clinically important prevalence estimates.

\section{Results}

Of the 600 subjects in the study samples, 552 (92\%) returned follow up questionnaires. In a few cases some answers were incomplete, and totals in columns in tables II and III therefore vary slightly.

One hundred and eighty one $(87 \%)$ men and 371 $(95 \%)$ women returned the questionnaires. Table I gives the characteristics of these subjects at the initial examination. There were no significant differences between respondents and non-respondents in either sex. In addition, among the respondents there were no significant differences between men and women in any of the variables examined by the follow up questionnaire, and results were therefore combined.

Table II shows that most people with a blood cholesterol concentration greater than $6.5 \mathrm{mmol} / \mathrm{l}$ thought that the value was high $(\mathrm{n}=99 ; 81 \%(95 \%$ confidence interval $74 \%$ to $88 \%$ )), returned to their doctor because of their cholesterol concentration $(\mathrm{n}=102 ; 82 \%(75 \%$ to $89 \%))$, and reported changing their diet $(n=93 ; 75 \%(67 \%$ to $83 \%))$. In comparison, people without high blood cholesterol concentrations were significantly less likely to think that their values were high or return to their doctor, and they were also significantly less likely to report changing their diet to reduce the concentration $\left(\chi^{2}=124 \cdot 2 ; \mathrm{df}=2 ; \mathrm{p}<0.0001\right)$.

Overall, $333(61 \%)$ of all respondents who answered reported not changing their diet to reduce their cholesterol concentration. Of these, $266(80 \%)$ reported not changing their diet because they believed that their cholesterol concentration was "all right." From the perspective of the whole sample $49 \%$ ( $n=226 / 542 ; 95 \%$ confidence interval $45 \%$ to $53 \%$ ) of people did not change their diet for that reason. More people with a blood cholesterol concentration of $5.5 \mathrm{mmol} / 1$ or less did not change their diet for that reason $(n=193 ; 74 \%)$ compared with those with the middle range of values $(n=59 ; 37 \%)$ and those with the high range $(n=14$; $11 \%)$.

Table III lists the doctors' comments and actions which were recalled by the 208 people who returned to their doctor. Most people with high cholesterol concentrations recalled being told by their doctor that their concentration was high $(n=78 ; 79 \%)$, and 87 of 96 (91\%) respondents recalled their doctor advising them to lower their concentrations. Repeat tests, however, were organised for only 46 of 100 respondents with high concentrations.

Eighty two per cent $(\mathrm{n}=83 ;(74 \%$ to $90 \%))$ of respondents with high cholesterol concentrations recalled receiving dietary advice, but advice to reduce other important risk factors for heart disease was recalled by less than half of those with high concentrations. Lipid lowering agents were begun in 14 subjects - namely, cholestyramine in eight cases; clofibrate in two; and combinations of cholestyramine, clofibrate, and nicotinic acid in three. One subject did not give the name of the drug.

Of the subjects without a high cholesterol concentration who returned to their doctor, more reported their doctor saying that they did not need to lower their concentrations, including $61 \%(n=27 ;(47 \%$ to $75 \%))$ of respondents with values of $5.5 \mathrm{mmol} / \mathrm{l}$ or less. They 
were also significantly less likely to recall advice to lower their cholesterol concentrations $(p<0.001)$ and significantly less likely to recall receiving dietary advice from their doctor $(p<0 \cdot 001)$.

\section{Discussion}

The success of case finding to identify people with high blood cholesterol concentrations relies on the completion of several crucial steps from testing to changing the diet and sometimes taking lipid lowering agents. In this study $102(82 \%)$ of 124 respondents with high cholesterol concentrations reported visiting their doctor and $82 \%$ of these reported receiving dietary advice to lower the concentration. Individually these steps have good success rates, but taken together they indicate that only two thirds of people identified with high cholesterol values report receiving the advice that they need from their doctor. The response to the question, "Did you change your diet to reduce your cholesterol concentration?" also indicated that a quarter of people who were informed that they had a high cholesterol concentration did not attempt to change their diet (table II). A reported change in diet may not always indicate a change that will reduce the blood cholesterol concentration, and these results are therefore likely to overestimate useful changes in diet.

Thus case finding does not lead to everyone with a high cholesterol concentration reducing his or her risk, and the effectiveness of this strategy in people with moderately high values is even less impressive. This important observation is not due to a poor response at any one step but due to a small but important drop out at each step in the high risk strategy.

The results for visiting the doctor and receiving dietary advice were slightly better than those reported in two studies in North America. In the Minnesota heart health programme $58 \%$ of people with high cholesterol concentrations $(>6.9 \mathrm{mmol} / \mathrm{l})$ detected by screening saw their doctor by six months and $73 \%$ of these were told to reduce their fat and cholesterol intakes. ${ }^{8}$ In a New York study, however, only $33 \%$ of people with cholesterol concentrations greater than $5.7 \mathrm{mmol} / \mathrm{l}$ saw their doctor and $36 \%$ of these said that they received dietary advice from their doctor. ${ }^{9}$ Although case finding may have better return rates than community screening, it seems that many people who are advised to see their doctor because of high blood cholesterol concentrations do not visit within several months of a blood test.

Of equal concern is the outcome in people with cholesterol concentrations of $6.5 \mathrm{mmol} / \mathrm{l}$ or less. Results from the multiple risk factor intervention cohort suggest that most people with this range of values are at some risk of heart disease.$^{10}$ In our study, however, many people with this range of values were told by their doctor that they did not need to reduce their cholesterol concentration and, overall, most had not changed their diet because they believed that their concentration was satisfactory. If case finding or mass screening discourages half the population from changing their diet this will seriously limit the effect of population strategies aimed at reducing the incidence of heart disease. From the population perspective the importance of lowering cholesterol values in people with low to moderate concentrations is highlighted by results from over 300000 men in the multiple risk factor intervention cohort. After six years of follow up $30 \%$ of deaths due to heart disease occurred in men with cholesterol concentrations less than $5.2 \mathrm{mmol} / \mathrm{l}$ and $60 \%$ occurred in men with concentrations less than $6 \cdot 2 \mathrm{mmol} / \mathrm{l}^{10}$

Our results suggest that the high risk strategy of case finding should not be regarded as highly effective in detecting and treating people with high cholesterol concentrations. Indeed, given that two thirds of the sample were women, case finding in general practice may not be the most efficient method of detecting people at high risk of heart disease. These factors should be taken into account in heart disease prevention models which estimate the impact of different strategies on heart disease prevention.

It also seems that high risk strategies which require a cholesterol test in all adults have the potential to interfere with national strategies designed tö reduce the risk of heart disease in populations as a whole. Despite the theoretical appeal of achieving additive effects from employing both methods of prevention, ${ }^{6}$ it seems that this high risk strategy and population strategies are not complementary in practice. One reason for this in our series may have been the lack of advice given to people whose blood cholesterol concentrations were not high. A change that might reduce the adverse effects of case finding for high cholesterol values would be to ensure that people without high cholesterol concentrations are informed that they can reduce their risk further by making appropriate changes in their lifestyle. Another option would be to lessen the emphasis on current recommendations to screen all adults and adopt a more selective approach, such as screening only people who are likely to have high cholesterol concentrations ${ }^{7}$ or who are at higher risk of heart disease (for example, those with a history of heart disease or hypertension).

We thank Dawn Sneddon, Heather Powell, and Joanne Kinlay for data collection, and Astra Pharmaceuticals (Australia) for financial support. SK was supported by a National Health and Medical Research Council (Australia) public health research and development fellowship.

1 National Heart Foundation of Australia. Update on diet and heart disease. Canberra: National Heart Foundation, 1987. (Update series No 1.)

2 Study Group of the European Atherosclerosis Society. Strategies for the prevention of coronary heart disease: a policy statement of the European prevention of coronary heart disease: a policy state
Atherosclerosis Society. Eur Heart f 1987;8:77-88.

3 National Cholesterol Education Programme Expert Panel on Detection, Evaluation and Treatment of High Blood Cholesterol in Adults. Report. Evaluation and Treatment of High

4 Jacobs DR, Barrett-Connor E. Retest reliability of plasma cholesterol and triglycerides. The Lipid Research Clinics prevalence study. Am f Epidemio 1982;116:878-88.

5 Rose G. Sick individuals and sick populations. In $\mathcal{f}$ Epidemiol 1985;14:32-8.

6 Lewis B, Mann JI, Mancini M. Reducing the risk of coronary heart disease in individuals and in the population. Lancet $1986 ; 1: 956-9$.

7 Kinlay S, Heller RF. Selective screening for high cholesterol in Australian general practice: the Newcastle cholesterol prediction study. 7 Gen Interm Med 1990;5:1-8.

8 Rastam L, Luepker RV, Pirie PL. Effect of screening and referral on follow-up and treatment of high cholesterol levels. Amerian fournal of Preventive Medicine. 1988;4:244-8.

9 Wynder EL, Field F, Haley NJ. Population screening for cholesterol determination: a pilot study. FAMA 1986;256:2839-42.

10 Martin MJ. Hullev SB, Browner WS, et al. Serum cholesterol, blood pressure, and mortality: implications from a cohort of 361662 men. Lancet 1986 ;ii: 933-6.

(Accepted 30 March 1990) 